\title{
PERIOPERATIVE BLOOD TRANSFUSIONS AND DECREASED LONG-TERM SURVIVAL IN ESOPHAGEAL CANCER
}

Stephen G. Swisher, MD ${ }^{a *}$

E. Carmack Holmes, MD $^{\text {b }}$

Kelly K. Hunt, MD ${ }^{\text {c* }}$

Jeffrey A. Gornbein, DrPH ${ }^{\mathrm{d}}$

Michael J. Zinner, MD ${ }^{\text {** }}$

David W. McFadden, MD
We evaluated retrospectively the effect of perioperative blood transfusions on survival in esophageal cancer. The records of all patients who underwent esophageal resection ( $n=316$ ) at UCLA Medical Center from 1970 to 1993 were reviewed. Statistical analysis included univariate (log-rank $\chi^{2}$ ) and multivariate (Cox proportional hazards) analyses with other known risk factors. High-volume blood transfusions ( $>8$ units) but not low-volume blood transfusions ( 1 to 8 units) were associated with a significant decrease in long-term survival (median survival: no transfusion, 22 months; lowvolume blood transfusion, 14.5 months, versus high-volume blood transfusions, 6.5 months; $p<0.01$ ). Multivariate analysis revealed that the shorter survival with high-volume blood transfusions was a result of an increased number of postoperative complications. High-volume blood transfusions were not associated with increases in tumor recurrence or infectious complications. The association between shorter survival and high-volume blood transfusions in esophageal cancer may, therefore, be because of the circumstances necessitating transfusion rather than any immunosuppressive effects of the transfused blood. These findings suggest that the transfusion of blood does not by itself decrease the chance of cure after esophageal resection. (J Thorac Cardiovasc Surg 1996;112:341-8)
P erioperative blood transfusions have been associated with decreased survival in various types of cancer, including colorectal, lung, hepatocellular, gastric, head and neck, renal, prostate, and sarcoma. $^{1-8}$ No study to date has evaluated the effect of

From the Departments of Surgery and Biostatistics ${ }^{\mathrm{d}}$ and Divisions of Thoracic Surgery, ${ }^{\mathrm{b}}$ General Surgery, ${ }^{\mathrm{a}}$ and Surgical Oncology, ${ }^{c}$ University of California at Los Angeles Medical Center, Los Angeles, Calif.

Presented at the forty-eighth annual cancer symposium of The Society of Surgical Oncology, Boston, Mass., March 23-26, 1995.

Received for publication May 11, 1995; revisions requested July 20, 1995; revisions received Nov. 20, 1995; accepted for publication Nov. 21, 1995.

Address for reprints: Stephen G. Swisher, MD, Department of Thoracic and Cardiovascular Surgery, Box 109, The University of Texas M. D. Anderson Cancer Center, 1515 Holcombe Blvd., Houston, TX 77030.

*Current addresses: Department of Thoracic and Cardiovascular Surgery, Box 109 (S.G.S.), and Department of Surgical Oncology, Box 106 (K.K.H.), The University of Texas M. D. Anderson Cancer Center, 1515 Holcombe Blvd., Houston, TX 77030; Department of General Surgery (M.J.Z.), Brigham and Women's Hospital, Boston, MA 02115.

Copyright (C) 1996 by Mosby-Year Book, Inc.

$0022-5223 / 96 \$ 5.00+0 \quad \mathbf{1 2 / 1 / 7 0 7 9 8}$ perioperative blood transfusions on survival in esophageal cancer. Furthermore, many of these prior studies failed to control for all prognostic factors, including the preoperative status of the patient, tumor stage, and perioperative outcome. We set out, therefore, to evaluate the effect of transfusions of blood and other serum-based products (fresh-frozen plasma [FFP], albumin, and platelets) on survival after esophageal resection. Our study involved multivariate analysis with other prognostic factors and sought to determine whether blood transfusions were an independent risk factor for decreased survival in esophageal cancer.

\section{Methods}

Patient data. The hospital records of all patients $(n=$ 316) who underwent esophageal resection because of adenocarcinoma or squamous cell carcinoma at UCLA Medical Center between January 1, 1970, and June 1, 1993, were reviewed. To assess the role of perioperative blood transfusions on long-term survival, all patients who did not undergo complete resection of the primary tumor were excluded, along with patients who died within 30 days of operation. A total of 275 patients fit the study criteria and these cases were carefully reviewed for various factors, including age, race, tumor location, histologic type, grade, pathologic and clinical stages, presenting symptoms, and preoperative medical history and performance status. 


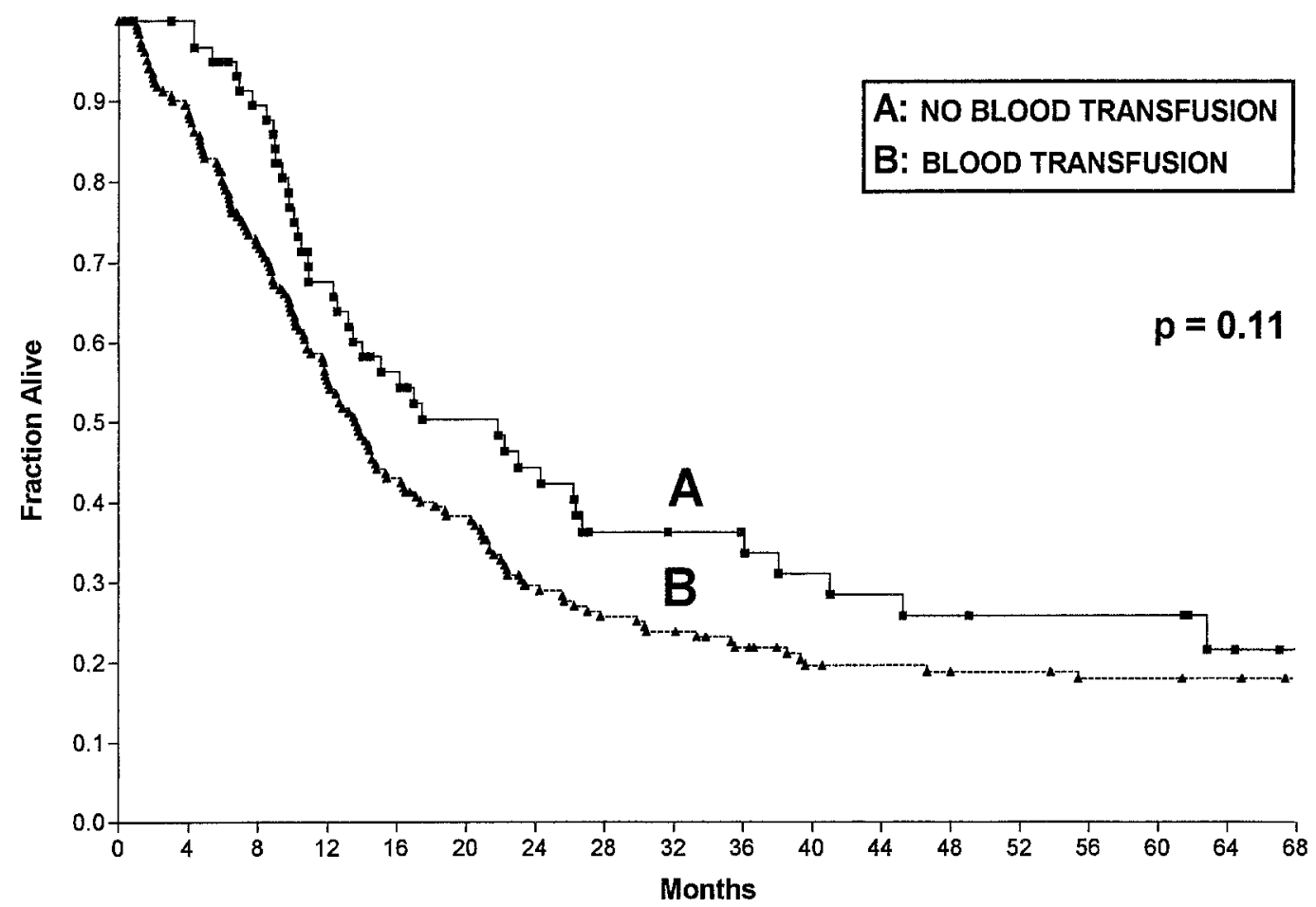

Fig. 1. No significant decrease was seen in overall survival duration of patients who underwent esophageal resection and received blood transfusions. Median survival of patients who received no blood transfusion (line $A, n=61$ ) was 21.8 months and for those who received blood (line $B, n=191$ ) was 13.7 months $(p=$ $0.11)$.

Complete perioperative data on blood-product transfusion were available for 252 patients and were used for survival analysis. The perioperative period was defined as 48 hours before and 48 hours after operation. Experienced surgeons were defined as those who had done more than 10 esophagectomies. Patient treatment during this period was carefully evaluated for the amount and types of fluid transfused (packed red blood cells [PRBC], whole blood, autologous blood, platelets, FFP, albumin, and crystalloid), the number and duration of hypotensive episodes (defined as periods with mean arterial pressure less than $80 \%$ of preoperative value), and need for inotropic support. The operative and anesthesia times, blood loss, type of operation, and location of anastomoses were recorded.

Short-term outcome was assessed by the number and types of postoperative complications, including the need for extended hospitalization and reoperation. Postoperative changes in laboratory values were assessed 3 days after operation and included lymphocyte counts, hematocrit values, liver function test results, and coagulation profiles. Long-term outcome was determined by review of outpatient records and through the database of the UCLA Tumor Registry. Recurrences, postoperative treatments, and status at most recent follow-up were noted.

Statistical analysis. Statistical analysis was done only on the 275 patients who underwent complete resections of the primary tumor and did not die within 30 days.
Univariately, $\chi^{2}$ (log likelihood ratio) tests were used for estimating and comparing death rates on the basis of the Poisson distribution. Conditional Poisson methods were used to estimate confidence bounds. Product-limit survival curves were computed by the methods of Kaplan and Meier and the log-rank test was used for comparing survival curves. Multivariately, the stepwise Cox proportional hazards model was used to simultaneously assess the impact of many factors on survival. Liberal $(p<0.10)$ inclusion criteria were used for variable inclusion. The SAS statistical package (SAS Institute, Cary, N.C.) was used for all analyses. Statistical significance was accepted as $p<0.05$.

\section{Results}

Effect of blood transfusions on survival duration in esophageal cancer. Complete records were available for 252 patients. Preoperative chemotherapy was used in 28 patients and preoperative radiation therapy was used in 47 . A total of 30 surgeons performed esophagectomies, but three surgeons performed the majority of the operations (141/252, $56 \%$ ). Transthoracic resection was used in 207 patients (Ivor-Lewis, 190; left side of the chest, 12; right side of the chest and neck anastomosis, 5), 
whereas 45 patients underwent transhiatal esophagectomy. A total of 191 patients $(76 \%)$ received blood products (PRBC, whole blood, or autologous), whereas 61 patients (24\%) received no transfusions. The amount of blood transfused was 0 units in 61 patients (24\%), 1 to 4 units in 116 patients $(46 \%), 5$ to 8 units in 48 patients $(19 \%)$, and more than 8 units in 27 patients $(11 \%)$.

The median survival duration of patients who did not receive blood was 21.8 months whereas that of patients who did receive blood was 13.7 months (Fig. 1). This difference approached significance $(p=0.11)$ when subjected to log-rank $\chi^{2}$ analysis. Univariate analysis of the risk relative to the amount of blood transfused showed that the risk rose dramatically with transfusions greater than 8 units (Table I). Multivariate analysis confirmed a blood transfusion threshold of 8 units, above which the risk ratio rose from 1.12 to 2.16 (Table II). When the amount of blood transfused exceeded 8 units the median survival was 6.5 months $(p<0.01)$ compared with 14.5 months for 1 to 8 units and 22 months for no blood transfusion (Fig. 2).

Multivariate analysis of the effect of perioperative blood transfusion. High-volume blood transfusion was associated with significantly more intraoperative blood loss, hypotension, and transfusions of albumin and crystalloid. No difference was seen between groups in preoperative status or tumor extent. Because of these observed perioperative differences, a univariate analysis was done with 45 other risk factors, including tumor characteristics, preoperative patient status, and perioperative treatments to determine significant variables to evaluate multivariately (Table III). With use of a liberal inclusion scheme $(p<0.10)$ all factors deemed significant with univariate analysis were evaluated by multivariate analysis. The five significant prognostic factors for esophageal cancer in multivariate analysis were four measures of tumor extent (grade, depth, lymph node status, and presence of metastases) and one perioperative factor (high-volume blood transfusions of $>8$ units) (Table I). Other factors such as blood loss, anastomosis location, FFP transfusion, platelet and albumin transfusion, gender, clinical tumor stage, tumor size, alcohol use, hematocrit value at admission to the hospital, percent of positive lymph nodes, distant recurrence, lymphocyte count, duration of intensive care unit (ICU) stay, surgeon experience, year of procedure, and percent tumor necrosis were associated with decreased survival duration in univariate analysis but did not
Table I. Relative risk of dying as a function of number of transfusions (univariate analysis)

\begin{tabular}{cccccc}
\hline $\begin{array}{c}\text { Transfusions } \\
\text { (units) }\end{array}$ & $\begin{array}{c}\text { No. of } \\
\text { patients }\end{array}$ & $\begin{array}{c}\text { Death } \\
\text { rate }\end{array}$ & $\begin{array}{c}\text { Relative } \\
\text { risk } t^{\prime}\end{array}$ & $\begin{array}{c}\text { Confidence } \\
\text { interval }\end{array}$ & $\begin{array}{c}p \\
\text { Valuet }\end{array}$ \\
\hline Missing & 23 & 3.22 & - & - & - \\
0 & 61 & 3.06 & 1.00 & - & - \\
1 & 24 & 4.61 & 1.51 & $0.85,2.66$ & 0.1160 \\
2 & 41 & 4.25 & 1.39 & $0.88,2.20$ & 0.1217 \\
3 & 26 & 2.13 & 0.52 & $0.39,1.24$ & 0.2606 \\
4 & 26 & 1.63 & 0.53 & $0.29,0.96$ & 0.0385 \\
5 & 16 & 7.68 & 2.51 & $1.37,4.60$ & 0.0026 \\
6 & 12 & 2.83 & 0.92 & $0.44,1.93$ & 0.9997 \\
7 & 10 & 2.77 & 0.91 & $0.42,1.96$ & 0.9781 \\
8 & 9 & 1.90 & 0.62 & $0.26,1.49$ & 0.3678 \\
9 & 3 & 33.80 & 11.05 & $2.59,47.05$ & 0.0018 \\
10 & 6 & 10.03 & 3.28 & $1.27,8.46$ & 0.0117 \\
11 & 4 & 11.60 & 3.79 & $1.33,10.82$ & 0.0106 \\
12 & 3 & 15.03 & 4.91 & $1.48,16.26$ & 0.0079 \\
13 & 1 & 0.00 & 0.00 & - & - \\
14 & 2 & 11.95 & 3.91 & $0.92,16.63$ & 0.0321 \\
$15+$ & 8 & 21.73 & 7.10 & $3.27,15.41$ & 0.0001 \\
Total & 275 & 3.30 & 1.08 & $0.91,1.28$ & - \\
\hline
\end{tabular}

${ }^{*}$ Death rate per 100 patient-months.

$\dagger$ Relative risk compared with 0 units

\$Statistical significance: $p \leq 0.05$.

remain significant in multivariate analysis. Even at very high volumes, transfusion of other serum-based products (FFP, platelets, albumin) had no effect on survival duration in multivariate analysis. There were no significant differences in survival among types of blood transfused (PRBC, whole blood, or autologous blood) or timing of transfusion (preoperative, intraoperative, or postoperative). High-volume blood transfusion was associated with a risk ratio of 2.17 compared with the risk ratios of grade (1.44), depth (1.37), lymph node status (2.28), and metastases (3.36).

Short- and long-term outcomes of patients receiving high-volume blood transfusions. We further evaluated the short- and long-term outcomes of patients receiving high-volume blood transfusion (Table IV). No increase was noted in the rates of local or distant tumor recurrence after high-volume blood transfusion. Furthermore, the rates of infectious complications were similar between the two groups. Patients who received high-volume blood transfusion also had a much higher risk of the development of more than four complications in the postoperative course (high-volume blood transfusion, $7 / 27$ [26\%] versus no transfusion or lowvolume blood transfusion, $3 / 225[1 \%] ; p<0.0001$ ), with increases in the lengths of both ICU and 


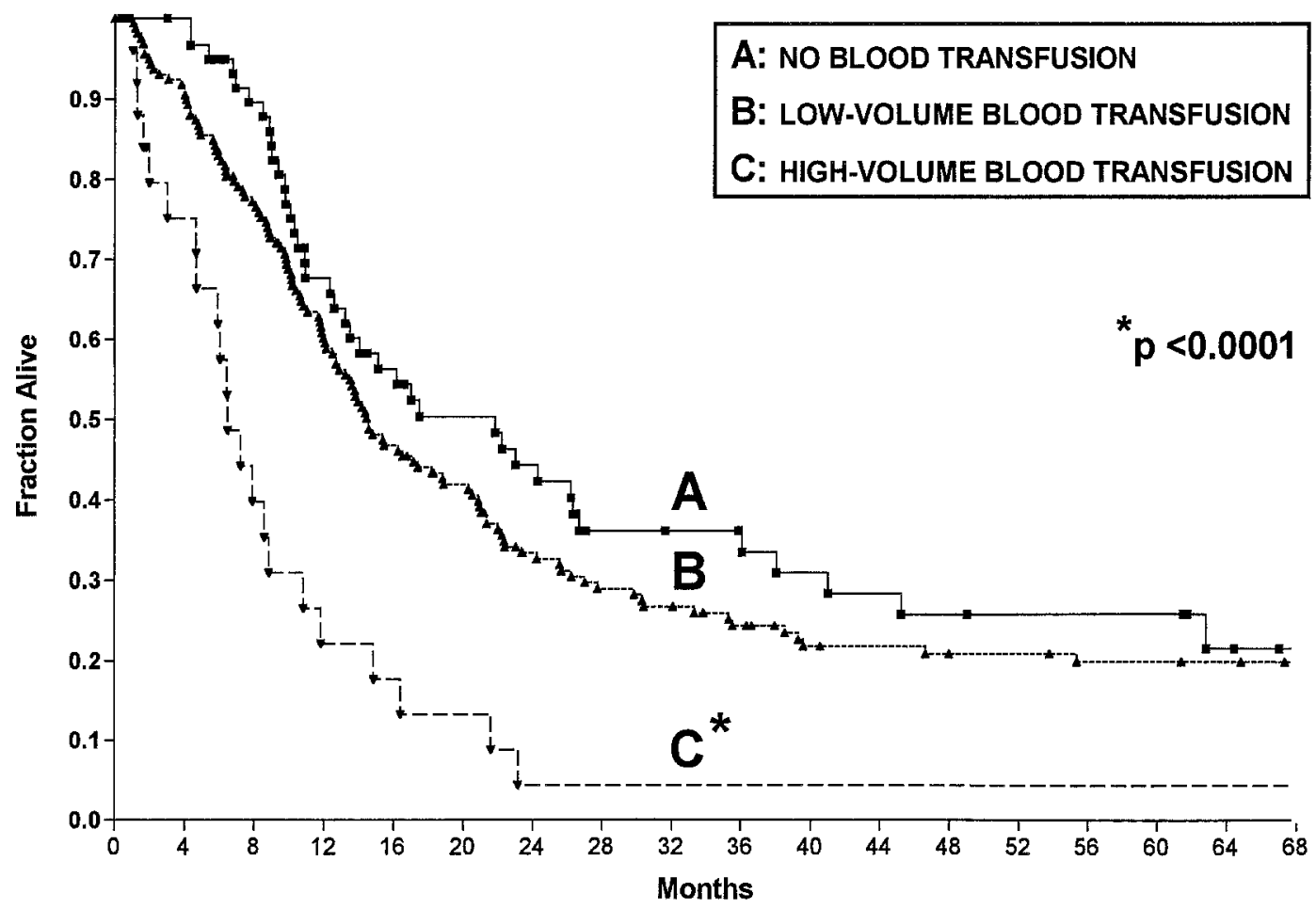

Fig. 2. Subset of patients who received high-volume blood transfusions ( $>8$ units) during esophageal resection had significant decrease in survival duration. Median survival for patients who received no transfusion (line $A, n=61$ ) was 22 months, for those who received low-volume transfusion (line $B, 1$ to 8 units, $n=164$ ) 14.5 months, and for those who received high-volume transfusion (line $C,>8$ units, $n=27$ ) 6.5 months $(p<0.001)$.

Table II. Risk of dying as a result of blood transfusions controlling for other risk factors (Cox model)*

\begin{tabular}{lccc}
\hline \multicolumn{1}{c}{ Factor } & $\begin{array}{c}\text { Relative } \\
\text { risk }\end{array}$ & $\begin{array}{c}95 \% \\
\text { Confidence interval }\end{array}$ & $\begin{array}{c}p \\
\text { Valuet }\end{array}$ \\
\hline Blood transfused & & & \\
$\quad$ 0 units & 1.00 & - & - \\
1-4 units & 0.96 & $0.64,1.43$ & 0.84 \\
4-8 units $\$$ & 1.02 & $0.63,1.65$ & 0.95 \\
$>8$ units $\$$ & 2.14 & $1.14,4.01$ & 0.01 \\
Lymph nodes & 2.29 & $1.56,3.35$ & 0.0001 \\
Poor grade & 1.43 & $1.04,1.97$ & 0.03 \\
Depth & 1.37 & $1.09,1.72$ & 0.006 \\
Metastases & 3.36 & $1.98,5.70$ & 0.0001 \\
\hline
\end{tabular}

*Multivariate analysis performed with factors listed in table and other significant univariate factors including blood loss, hypotension, gender, alcohol use, transfused platelets, FFP, and albumin, hematocrit value on hospital admission, tumor necrosis, weight loss, length of ICU stay, lymphocyte count, experience of surgeon, year of procedure, pathologic stage 1, stage $2 \mathrm{~A}$, stage $2 \mathrm{~B}$, stage 3 , stage 4 , lymph node positive percent, distant recurrence, operative blood use, Barrett's esophagus, and positive margins

† Statistical significance: $p \leq 0.05$.

$\$$ Relative risk compared with 0 units. regular hospital stays (Table IV). These complications occurred within 30 days of the operation and were associated with a significantly shorter survival (those with more than four complications had a 5-year survival of $0 \%$, whereas those who had fewer complications had a 5 -year survival of $24 \% ; p<0.0001$ ) (Fig. 3 ). The cause of death after high-volume blood transfusion was tumor recurrence in three patients, pulmonary failure in four patients, and late reoperations in three patients. This poor outcome explains in part the low overall survival of patients receiving high-volume blood transfusion. In fact, when the number of complications ( $>4$ versus 0 to 4 ) was included in the multivariate analysis, high-volume blood transfusion was no longer a significant predictor of survival duration in patients undergoing esophageal resection (Table V). The addition of postoperative complications to the multivariate analysis had no effect on the other four prognostic factors: tumor grade and depth, lymph node status, and metastases. 
Table III. Univariate analyses of selected prognostic factors for esophageal cancer

\begin{tabular}{|c|c|c|c|}
\hline Factor* & $\begin{array}{l}\text { Relative } \\
\text { risk }\end{array}$ & $\begin{array}{c}95 \% \\
\text { Confidence } \\
\text { interval }\end{array}$ & $\begin{array}{c}p \\
\text { Valuet }\end{array}$ \\
\hline \multicolumn{4}{|l|}{ Patient characteristics } \\
\hline Female gender & 0.630 & $0.45,0.88$ & 0.0059 \\
\hline ASA class & 1.080 & $0.86,1.36$ & NS \\
\hline Karnovsky scale value & 1.214 & $0.98,1.51$ & NS \\
\hline Cigarette use & 0.990 & $0.74,1.33$ & NS \\
\hline Alcohol use & 1.413 & $1.01,1.97$ & 0.0198 \\
\hline \multicolumn{4}{|l|}{ Tumor characteristics } \\
\hline Histologic type & 1.027 & $0.88,1.70$ & NS \\
\hline Location & 1.027 & $0.72,1.47$ & NS \\
\hline Grade & 1.663 & $1.25,2.20$ & 0.0003 \\
\hline Size & 1.088 & $1.02,1.16$ & 0.0063 \\
\hline Depth & 1.745 & $1.44,2.11$ & 0.0001 \\
\hline Lymph nodes & 1.085 & $1.05,1.12$ & 0.0001 \\
\hline Metastases & 4.902 & $3.05,7.88$ & 0.0001 \\
\hline \multicolumn{4}{|l|}{ Perioperative factors } \\
\hline Operative time & 1.001 & $0.03,39.97$ & NS \\
\hline Blood loss & 1.695 & $1.20,2.38$ & 0.0028 \\
\hline Hypotension & 1.056 & $0.98,1.14$ & 0.1401 \\
\hline Inotrope use & 1.068 & $0.78,1.47$ & $\mathrm{NS}$ \\
\hline \multicolumn{4}{|l|}{ Perioperative transfusions } \\
\hline Blood & 1.059 & $1.04,1.08$ & 0.0001 \\
\hline High volume ( $>8$ units) & 2.137 & $1.53,2.98$ & 0.0001 \\
\hline Platelets & 1.102 & $0.99,1.32$ & 0.0563 \\
\hline FFP & 1.140 & $0.93,1.62$ & 0.0691 \\
\hline Albumin & 1.099 & $1.04,1.16$ & 0.0010 \\
\hline
\end{tabular}

NS, Not significant.

*Other prognostic factors that were significant in univariate analysis included hematocrit value on hospital admission, tumor necrosis, weight loss, length of ICU stay, lymphocyte count, experience of surgeon, year of procedure, pathologic stage 1 , stage $2 \mathrm{~A}$, stage $2 \mathrm{~B}$, stage 3 , stage 4 , lymph node positive percent, distant recurrence, operative blood use, Barrett's esophagus and positive margins. Other prognostic factors that were not significant univariately included age, ulceration, lymphocyte count, change in lymphocyte count, albumin, creatinine value, transhiatal esophagectomy, and local recurrence.

†Statistical significance: $p \leq 0.05$.

These findings suggest that the decreased survival duration observed with high-volume blood transfusion may not have been caused by highvolume blood transfusion, but may only reflect its association with the more significant prognostic factor of having more than four postoperative complications (correlation coefficient $r=-0.49$, $p<0.001)$. Preoperative factors associated with more than four postoperative complications included a history of emphysema and more than 20 pounds of weight loss. No association was seen with age, gender, tumor stage, preoperative chemotherapy, or radiation therapy use and increased complications.
Table IV. Postoperative outcome of patients by volume of transfusion

\begin{tabular}{lccc}
\hline & $\begin{array}{c}\text { No or low } \\
\text { blood volume } \\
(0-8 \text { units }) \\
(n=230)\end{array}$ & $\begin{array}{c}\text { High } \\
\text { blood volume } \\
(>8 \text { units }) \\
(n=25)\end{array}$ & $\begin{array}{c}p \\
\text { Value }^{*}\end{array}$ \\
\hline Tumor recurrence & & & \\
$\quad$ Local & $9 / 225(4 \%)$ & $2 / 27(7 \%)$ & NS \\
$\quad$ Distant & $40 / 225(18 \%)$ & $3 / 27(11 \%)$ & NS \\
Infectious & $38 / 225(17 \%)$ & $6 / 27(22 \%)$ & NS \\
$\quad$ complications & & & \\
Total no. of & & & \\
$\quad$ complications & & & \\
0 & $87 / 225(39 \%)$ & $3 / 27(11 \%)$ & 0.008 \\
1-4 & $139 / 225(61 \%)$ & $15 / 27(56 \%)$ & NS \\
$>5$ & $3 / 225(1 \%)$ & $7 / 27(26 \%)$ & 0.0001 \\
Postoperative & & & \\
days in hospital & & & \\
ICU $\dagger$ & & & \\
Total $\dagger$ & $4.3 \pm 0.6$ & $16.8 \pm 16$ & 0.02 \\
\hline
\end{tabular}

NS, Not significant.

*Statistical significance: $p \leq 0.05$.

†Value plus or minus standard deviation.

\section{Discussion}

Perioperative blood transfusions have been associated with decreased long-term survival in various types of cancer, including colorectal, lung, hepatocellular, gastric, head and neck, breast, prostate, renal cell carcinoma, and sarcoma. ${ }^{2,3,5,6,8-11}$ Controversy exists because other reports have shown no decrease in survival with transfusions. ${ }^{12-20}$ One explanation for these discrepancies is that some studies included patients who died in the perioperative period whereas other studies did not. Furthermore, not all studies included multivariate analysis with important prognostic factors such as tumor stage and perioperative outcome. Our study took care not to bias long-term tumor survival with poor operative outcomes by excluding all patients who died within 30 days of operation. We also performed multivariate analysis with other important prognostic factors to determine whether blood transfusion was actually an independent predictor of long-term survival. Even with multivariate analysis, high-volume blood transfusion was a significant risk factor for decreased survival (Table III). As has been reported by others, this effect was most pronounced at high volumes of blood transfusion (Fig. 2), suggesting a possible threshold effect. ${ }^{4,8,21}$

Controversy exists as to whether the decreased survival duration observed with perioperative blood 


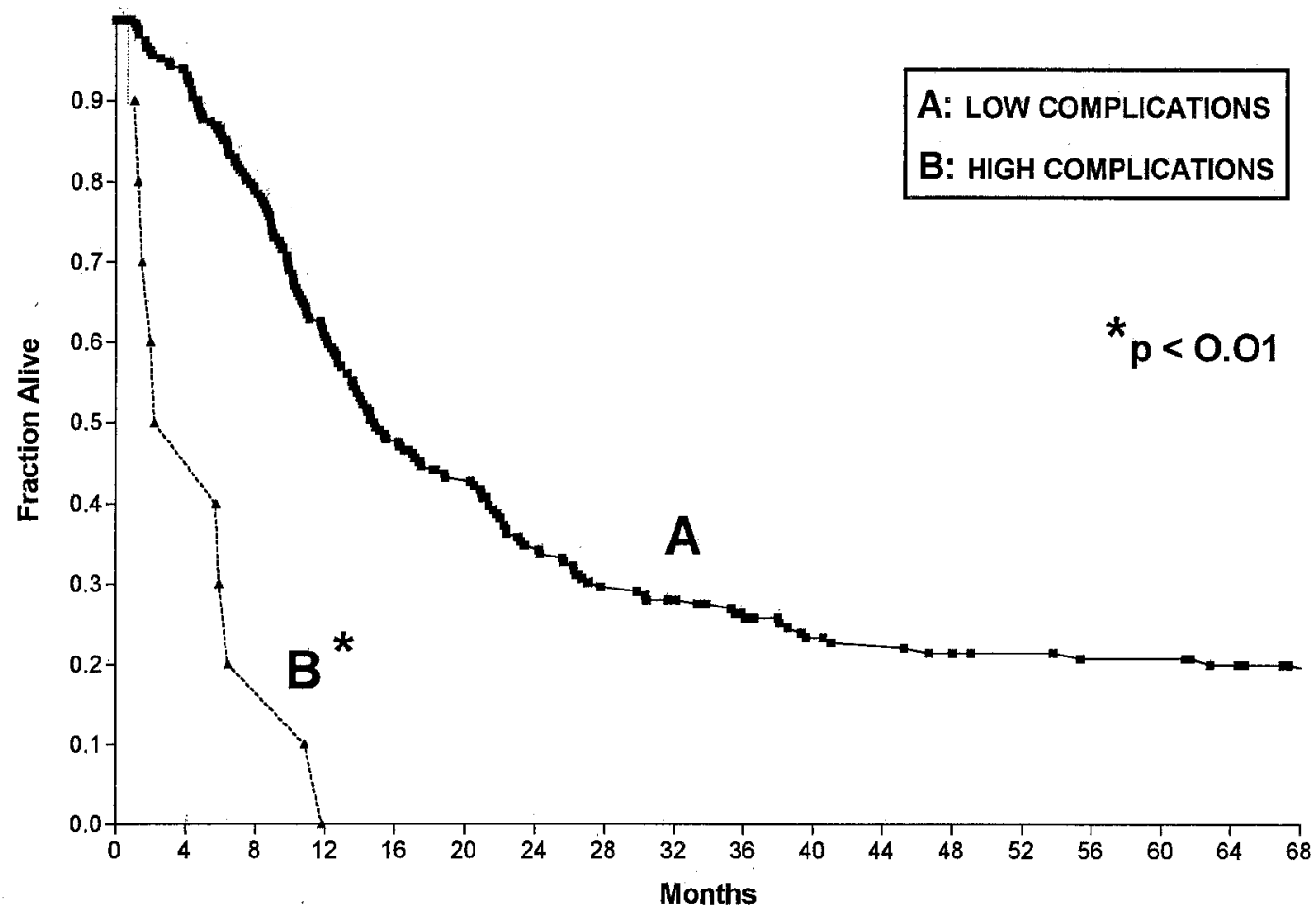

Fig. 3. Development of more than four postoperative complications after esophageal resection was associated with marked decrease in survival duration. For those who had more than four complications (line $B, n=10$ ), 5 -year survival was $0 \%$; for those who had four or fewer complications (line $A, n=242$ ), 5 -year survival was $24 \%(p<0.001)$.

Table V. Multivariate (Cox model) assessment of prognostic factors in esophageal cancer death with and without inclusion of postoperative complications

\begin{tabular}{|c|c|c|c|c|c|c|}
\hline \multirow[b]{2}{*}{ Factor } & \multicolumn{3}{|c|}{ Without complications } & \multicolumn{3}{|c|}{ Including complications } \\
\hline & $R R$ & $95 \% \mathrm{CI}$ & $p$ Value* & $R R$ & $95 \% C I$ & $p$ Value $^{*}$ \\
\hline Transfusions (>8 units) & 2.17 & $1.24,3.80$ & 0.006 & 1.42 & $0.68 ; 2.93$ & 0.34 (NS) \\
\hline Complications $(>4)$ & & Not included & & 3.44 & $1.30,9.10$ & 0.01 \\
\hline Poor grade & 1.44 & $1.05,1.98$ & 0.023 & 1.50 & $1.09,2.00$ & 0.01 \\
\hline Depth & 1.37 & $1.09,1.71$ & 0.006 & 1.36 & $1.09,1.70$ & 0.001 \\
\hline Lymph nodes & 2.28 & $1.56,3.34$ & 0.0001 & 2.14 & $1.46,3.10$ & 0.0001 \\
\hline Metastases & 3.36 & $1.98,5.71$ & 0.0001 & 3.48 & $1.98,5.76$ & 0.0001 \\
\hline
\end{tabular}

$R R$, Relative risk; $C I$, confidence interval; $N S$, not significant.

${ }^{*}$ Statistical significance: $p \leq 0.05$.

transfusions is a result of the causal effect of immune suppression by blood or of the close association with circumstances that necessitate transfusions (that is, large tumors that require much manipulation and blood loss to remove). The immunosuppressive effect of blood transfusion has been documented in other studies. The transfusion of blood is known to increase kidney transplant survival rates by decreasing episodes of rejection..$^{22}$ Recurrences of Crohn's disease have been reported to decrease after blood transfusion. ${ }^{23}$ Furthermore, specific immunorelated abnormalities have been documented after blood transfusion, including decreased natural killer cell function, ${ }^{24-26} \mathrm{de}$ pression of macrophage activity, ${ }^{27}$ low lymphocyte counts, ${ }^{28}$ and increased levels of the immunosuppressant prostaglandin $\mathrm{E}_{2} \cdot{ }^{27}$ Because transfusion-related immunosuppression is thought to be nonspecific, one would expect increases in tumor recurrences and in- 
fectious complications, as well as decreased survival duration, after transfusion. Indeed, various authors have documented increases in tumor recurrence and infections concomitant with perioperative transfusions in several cancers, including colon, hepatocellular, lung, and sarcoma. ${ }^{2,4,8,11,29-31}$ The patients in this study, however, showed no increases in either local or distant tumor recurrences, and infectious complication rates were the same even though the total number of complications was markedly increased with blood transfusions (Table IV). In addition, we saw no significant depression of lymphocytes after transfusion, as has been described by others. ${ }^{28}$ These findings suggest that a large inmunosuppressive effect was not present and perhaps other factors accounted for the shorter survival duration after blood transfusion.

In further analysis, we found that blood transfusions were associated with an increase in predominantly noninfectious complications, which were associated with a marked decrease in survival duration (Fig. 3). This observation raised the possibility that the decreased survival duration we observed with high-volume blood transfusion was a result not of the immunosuppressive effects of the transfused blood but rather of its close association with postoperative complications. Indeed, the addition of complications to our multivariate analysis eliminated blood transfusion as a significant predictor of decreased survival and at the same time had no effect on the other predictors. Because the complications were for the most part noninfectious and therefore not attributable to immune suppression, the transfusion of blood appears to be only a marker for poor outcome rather than a causative factor. The clinical ramifications of this finding are important because in many instances the transfusion of blood is essential for a good short-term outcome, and the withholding of blood could be detrimental to the immediate clinical situation.

To our knowledge, this is the first published study to evaluate the effect of blood transfusions on survival duration in esophageal cancer and to document the close association of blood transfusions and postoperative complications in patients with this disease. Whether these findings are applicable to other cancers remains to be determined. The biologic features of esophageal tumors may be different from those of other types of cancer and therefore not sensitive to the immunosuppressive properties of blood. Alternatively, the decrease in survival duration reported with other types of cancer after blood transfusion may also be related to an in- creased number of postoperative complications rather than any immunosuppressive effect of blood. It would be interesting if future studies evaluating the role of blood products on survival included postoperative complications in their analysis.

In summary, our study showed that there was an association between perioperative blood transfusions and decreased survival duration in esophageal cancer. The association, however, may not have been causally related to blood immunosuppression but rather to the poor clinical situation that necessitated blood transfusions, which led to an increased number of postoperative complications and a subset of patients with a resultant poor outcome. The transfusion of blood products should still be minimized when possible to avoid risks such as hepatitis, acquired immunodeficiency syndrome, anaphylaxis, and transfusion reaction. The clinician need not forego transfusion in esophageal cancer because of a fear that blood product immunosuppression will decrease cure after esophageal resection.

\section{REFERENCES}

1. Sugezawa A, Kaibara N, Sumi K, et al. Blood transfusion and the prognosis of patients with gastric cancer. J Surg Oncol 1989;42:113-6.

2. Yamamoto J, Kosuge T, Țakayama T, et al. Perioperative blood transfusion promotes recurrence of hepatocellular carcinoma after hepatectomy. Surgery 1994;11:303-9.

3. McClinton S, Moffat LEF, Scott S, Urbaniak SJ, Kemdge DF. Blood transfusion and survival following surgery for prostatic carcinoma. Br J Surg 1990;77:140-2.

4. Tartter PI. The association of perioperative blood transfusion with colorectal cancer recurrence. Ann Surg 1992;216: 633-8.

5. Younes RN, Rogatko A, Brennan ME. The influence of intraoperative hypotension and perioperative blood transfusion on disease-free survival in patients with complete resection of colorectal liver metastases. Ann Surg 1991;214:107-13.

6. Mikulin T, Powell CS, Urwin GH, Hamdy F, Fox M, Williams HL. Relation between blood transfusion and survival in renal adenocarcinoma. Br J Surg 1986;73:1036-7.

7. Hyman NH, Foster RS, Demeules JE, Costanza MC. Blood transfusions and survival after lung cancer resection. Am J Surg 1985;149:502-7.

8. Rosenberg SA, Seipp CA, White DE, Wesley R. Perioperative blood transfusions are associated with increased rates of recurrence and decreased survival in patients with high-grade soft-tissue sarcomas of the extremities. J Clin Oncology 1985;3:698-709.

9. Chung M, Steinmetz OK, Gordon PH. Perioperative blood transfusion and outcome after resection for colorectal carcinoma. Br J Surg 1993;80:427-32.

10. Fong Y, Karpeh M, Mayer K, Brennan MF. Association of perioperative transfusions with poor outcome in resection of gastric adenocarcinoma. Am J Surg 1994;167:256-60.

11. Moores DWO, Piantadosi S, McKneally ME. Effect of perioperative blood transfusion on outcome in patients with 
surgically resected lung cancer. Ann Thorac Surg 1989;47: 346-51.

12. Bock M, Grevers G, Koblitz K, Heim MU, Mempel W. Influence of blood transfusion on recurrence, survival and postoperative infections of laryngeal cancer. Acta Otolaryngol 1990;110:150-60.

13. Eickhoff JH, Andersen J, Laybourn C. Perioperative blood transfusion does not promote recurrence and death after mastectomy for breast cancer. Br J Surg 1991;78:1358-61.

14. Geer RJ, Brennan MF. Prognostic indicators for survival after resection of pancreatic adenocarcinoma. Am J Surg 1993; 165:68-73.

15. Hopkins MP, Morley GW. Stage IB squamous cell cancer of the cervix: clinicopathologic features related to survival. Am J Obstet Gynecol 1991;164:1520-9.

16. Keller SM, Groshen S, Martini N, Kaiser LR. Blood transfusion and lung cancer recurrence. Cancer 1988;62:606-10.

17. Moriguci S, Maehara Y, Akazawa K, Sugimachi K, Nose Y. Lack of relationship between perioperative blood transfusion and survival time after curative resection for gastric cancer. Cancer 1990;66:2331-5.

18. Ness PM, Walsh PC, Zahurak M, Baldwin ML, Piantadosi S. Prostate cancer recurrence in radical surgery patients receiving autologous or homologous blood. Transfusion 1992;32:31-6.

19. Pena CM, Rice TW, Ahmad M, Medendorp SV. Significance of perioperative blood transfusions in patients undergoing resection of stage I and II non-small-cell lung cancers. Chest 1992;102:84-8.

20. Doersten PV, Cruz RM, Selby JV, Hilsinger RLJ, Transfusion, recurrence, and infection in head and neck cancer surgery. Otolaryngol Head Neck Surg 1992;106:60-7.

21. Wobbes T, Joosen KHG, Kuypers HHC, Beerthuizen GIJM, Theeuwes AGM. The effect of packed cells and whole blood transfusions on survival after curative resection for colorectal carcinoma. Dis Colon Rectum 1989;32:743-8.
22. Twuyver EV, Mooijart RID, Berge IJM, et al. Pretransplantation blood transfusion revisited. N Engl J Med 1991;325: 1210-3.

23. Peters WR, Fry RD, Fleshman JW, Kodner IJ. Multiple blood transfusions reduce the recurrence rate of Crohn's disease. Dis Colon Rectum 1989;32:749-53.

24. Waymack JP, Femandes G, Yurt RW, et al. Effect of blood transfusions on immune function: part VI-effect on immunologic response to tumor. Surgery 1990;108:171-8.

25. Jensen LS, Andersen AJ, Christiansen PM, et al. Postoperative infection and natural killer cell function following blood transfusion in patients undergoing elective colorectal surgery. Br J Surg 1992;79:513-6.

26. Gascon P, Zoumbos NC, Young NS. Immunologic abnormalities in patients receiving multiple blood transfusions. Ann Intern Med 1984;100:173-7.

27. Okuno K, Ozaki M, Shigeoka $\mathrm{H}$, et al. Effect of packed red cell and white blood transfusion on liver-associated immune function. Am J Surg 1994;168:340-4.

28. Ziv Y, Shohat B, Gelerenter I, Wolloch Y. B lymphocyte changes induced by perioperative blood transfusions and surgery in patients with colorectal cancer. Israel $\mathbf{J}$ Med Sci 1991;27:75-8.

29. Braga M, Vianalil A, Radaelli G, Gianotti L, Carlo VD. Association between perioperative blood transfusions and postoperative infection in patients having elective operations for gastrointestinal cancer. Eur J Surg 1992;158: 531-6.

30. Heiss MM, Mempel W, Jauch K-W, et al. Beneficial effect of autologous blood transfusion on infectious complications after colorectal cancer surgery. Lancet 1993;342: 1328-33.

31. Ford CD, VanMoorleghem G, Menlove RR. Blood transfusions and postoperative wound infection. Surgery 1993;113: 603-7. 